\title{
As narrativas de formação nos processos formativos de professores como dispositivo para a reflexão sobre a aprendizagem da docência na educação de jovens e adultos
}

\begin{abstract}
Resumo: O artigo aborda questões referentes ao uso de narrativas na formação de professores da Educação de Jovens e Adultos (EJA). O estudo apresenta como análise o processo de constituição da docência em EJA de cinco professoras de escolas públicas de Fortaleza-Ce. Os dados foram construídos a partir de narrativas escritas pelas professoras durante o curso de formação continuada. A abordagem teórica adotada foi a (auto) biográfica, numa perspectiva de investigação-formação e no modelo interativo-dialógico. (BASTOS, 2003; HERNÁNDEZ, 2006; JOSSO, 2004; PINEAU, 2006; SOUZA, 2006, 2008) Para refletir sobre a formação docente buscamos contribuição de autores como Mizukami e colaboradores (2002), Huberman (1992), Garcia (1999). Esses estudos evidenciam a experiência pessoal do professor como base para a formação docente, seja inicial ou continuada. A análise apreendida revelou que, de inicio, as professoras conceberam a docência em EJA como um desafio, o qual, enfrentaram buscando "novos fazeres" em sala de aula. Tal atitude contribuiu para um processo de identificação delas com a docência nessa modalidade de ensino.
\end{abstract}

Palavras-chave: Educação de Jovens e Adultos. Professores - Formação. (Auto) biografia.

\section{Introdução}

[...] é a narrativa que faz de nós o próprio personagem de nossa vida; é ela, enfim, que dá uma história a nossa vida: não fazemos a narrativa de nossa vida porque temos uma história; temos uma história porque fazemos a narrativa de nossa vida. (DELORY-MOMBERGER, 2008, p. 37)

$\mathrm{Na}$ convicção de que temos uma história de vida rica em experiências e que ao refletirmos e publicarmos damos sentido a nossa existência, buscaremos, nesse artigo, refletir sobre a vida profissional de professores da Educação de Jovens e adultos (EJA). Para tanto, partiremos da análise de narrativas escritas de professoras da EJA de escolas públicas de Fortaleza-CE, que participaram do curso de formação continuada intitulado Educação Profissional
Natal Lânia Roque Fernandes Professora do Instituto Federal de Ciência e Tecnologia do Ceará natallania@ifce.edu.br

Maria Amélia Lopes Professora da Universidade do Porto

amelia@fpce.up.pt 
Integrada ao Ensino Médio na modalidade de Educação de Jovens e Adultos, desenvolvida pelo Instituto Federal de Educação, Ciências e Tecnologia do Ceará (IFCE), durante a disciplina de História da Educação de Jovens e Adultos e da Educação Profissional.

O objetivo de trabalhar com narrativas foi desenvolver um processo formativo que valorizasse os saberes e as práticas dos professores, e, assim, contribuir para o fortalecimento das identidades dos docentes em formação. Essa necessidade fundamentou-se no fato de, sendo professoras há algum tempo, formando professores e pesquisando sobre a profissão docente, sabermos quanto o exercício de escrever sobre si contribuiu para o fortalecimento da subjetividade e para o processo de refletir sobre a profissão.

A leitura das narrativas nos despertou sensibilidade à história das professoras, perscrutando a pessoa presente no professor. Com isso, lançamos um olhar investigativo nos relatos escritos, buscando indícios do processo constitutivo da docência das profissionais em formação. Por fim, os indícios nos levaram a perceber: as influências que as professoras receberam para a escolha do magistério; como iniciaram na EJA; a construção do seu saber fazer cotidiano e os processos de mudança.

Nesse caso, a abordagem (auto)biográfica foi utilizada na perspectiva de investigação-formação, e no modelo interativo-dialógico (PINEAU, 2006), visto que, professores e formadora, conjuntamente, deram sentido ao enredo. Em outras palavras, os professores escreveram suas histórias em um processo de construção conjunta em que o diálogo e a reflexão sobre a escrita foi uma constante. Vale ressaltar que

[...] Este caráter dialógico e interativo da narrativa ancora-se, também, na complexidade de outros discursos, exprimindo uma intextualidade que nos remete para o mundo sociocultural da produção dos factos narrados. (LOPES et al., 2007, p. 22)

Desta forma, em um processo dialógico, os professores narraram sobre sua história através do tempo, tentando reconstruir os fatos vivenciados e transmitir as experiências que adquiriram, onde se delinearam as relações com os membros de seu grupo, de sua profissão, de sua pertença social, de sua sociedade global. (QUEIROZ apud BASTOS, 2003) Assim sendo, contando a sua história, os professores reconstituem a sua cultura, seu tempo, suas histórias, transcendendo do singular para a totalidade histórica, 
buscando situar-se entre "a história que fez e a história que o fez". (NORA apud BASTOS, 2003)

Durante o estudo da disciplina, os professores foram incentivados a escreverem sobre seu processo identitário docente, entrecruzando sua vida profissional com a história da educação. Neste artigo, serão discutidas as narrativas de cinco professoras que apresentaram em seus relatos algumas experiências semelhantes entre si.

As análises desenvolvidas tiveram como suporte teórico-metodológico os estudos sobre a abordagem (auto)biográfica (BASTOS, 2003; HERNÁNDEZ, 2006; JOSSO, 2004; PINEAU, 2006; SOUZA, 2006, 2008), bem como sobre a formação docente. (GARCIA, 1999; HUBERMAN, 1992; MIZUKAMI et al., 2002) A partir desses estudos, partimos do princípio de que a experiência pessoal do professor pode servir como base para a formação docente, seja inicial ou continuada, pois o ato de refletir a vida provoca um repensar das ações e da forma de aprender a profissão.

Neste texto, no primeiro momento, apresentaremos as discussões sobre a abordagem biográfica; em seguida, faremos uma incursão sobre as diferentes concepções de formação docente; e, no terceiro momento, apresentaremos as reflexões sobre as narrativas elaboradas pelas professoras.

\section{A abordagem (auto) biográfica: revisitando o percurso}

Desde as últimas décadas do século XX até os dias atuais, observa-se um crescimento no uso da abordagem biográfica, na acepção de pesquisas narrativas ou com histórias de vida em diversas áreas de conhecimentos das Ciências Sociais e Humanas. Principalmente na educação, é utilizada tanto como dispositivo de formação docente, constituindo-se como meio para a compreensão das dimensões pessoal e profissional do professor, quanto em pesquisas acadêmicas, como método de acesso ao percurso de vida e formação de diversos sujeitos da educação.

Nesse sentido, Josso (2004) afirma que os estudos sobre histórias de vida têm circulado em dois grandes eixos: as histórias de vida como projetos de conhecimento e história de vida a serviço de lógicas de projeto. Para essa autora, 
[...] as histórias de vida postas ao serviço de um projeto são necessariamente adaptadas à perspectiva definida pelo projeto no qual elas se inserem, enquanto que as histórias de vida, no verdadeiro sentido do termo, abarcam a globalidade da vida em todos os seus aspectos, em todas as suas dimensões passadas, presentes e futuras e na sua dinâmica própria. (JOSSO, 2004, p. 51)

Decerto, as investigações nessa área, direcionadas a projetos ou à globalidade de vida dos sujeitos, têm deslocado o professor do papel de coadjuvante para autor de sua profissão e valorizado as experiências por ele adquiridas em seu percurso profissional. Como afirma Hernández (2006, p. 229),

En la medida em que la historia de vida profesional posibilita um processo de reconstrución y señalizacion de temáticas constitutivas de modos de pensar y actuar el professor pued, y más si lo hace em contextos grupales, reconocerse y reposicionarse.

Como método de pesquisa, as histórias de vida foram introduzidas nas ciências sociais sob a influência da Escola de Chicago, com a publicação do Paysan Polonais, de W.I. Thomas e F. Znaniecki, no início do século XX. Em tal trabalho, a partir da abordagem em histórias de vida, o pesquisador retratou a realidade de imigrantes nos Estados Unidos e problemas sociais concernentes à época. Na Alemanha, Wilhelm Dilthey (1910) introduziu a perspectiva nas ciências humanas, considerando-a como uma hermenêutica da experiência e compreensão da vida, a qual tem grande influência nos estudos atuais com (auto)biografias. Com a Segunda Guerra Mundial, há um retraimento desse tipo de pesquisa, que é revitalizada com trabalhos na área da Antropologia, da Sociologia e da Psicologia , apenas na década de 1960. (JOSSO, 2004; PINEAU, 2006)

A retomada das investigações, nesse campo, acontece no contexto de mudanças de paradigmas, em relação à história cultural, em que emerge a valorização pelos processos cotidianos das práticas culturais. O movimento surgido na área social influenciou as Ciências da Educação, que desde o final da década de 1970 vêm desenvolvendo investigações com histórias de vida na perspectiva da formação. De acordo com Nóvoa (1992, p. 19, grifo do autor), "[...] o movimento nasceu no universo pedagógico, numa amálga- 
ma de vontades de produzir um outro tipo de conhecimento, mais próximo das realidades educativas e do quotidiano dos professores".

Tomando como parâmetro as datas da edição de produções escritas, de fundação de associações, de rede e de diplomas de formação, Gaston Pineau (2006) evidencia três períodos, que vão de 1980 a 2005, em que o movimento de histórias de vida e formação se tem destacado. O primeiro período foi caracterizado de período de eclosão, tendo como marcos a publicação de seu livro Produire sa vie: autoformation et autobiographie e a formação da rede sobre História de vida e formação, ambos em 1983; o lançamento de dois números da revista francesa Education permanente intitulados Les histoires de vie entre la recherche et la formation, em 1984; a realização de um colóquio sobre histórias de vida na Universidade de Tours, França; a publicação do livro O método (auto)biográfico e a formação, de Antonio Nóvoa e Matthias Finger da Universidade de Lisboa, que foi reeditado no Brasil no ano de 2010, pela editora da UFRN e a Paulus; e a obra Histoires de vie, publicada em dois tomos, sob a coordenação de Pineau e Jobert (1989). Essas publicações representam a gênese de uma mudança paradigmática na pesquisa científica, buscando dar outros sentidos aos acontecimentos pessoais e sociais no processo formativo dos indivíduos.

O segundo período, identificado por Pineau como período de fundação, tem início com a criação da L'Association Internacionale des histoires de vie en fomation (ASIHVIF), em 1990. Em seguida, assistiu-se à organização em diversos países de associações e redes nacionais e regionais, tais como na Suiça, em Quebec e em França. Assiste-se também ao lançamento em Paris da Coleção Histoire de vie et formation, em 1996, que tem garantido o espaço de publicação na área. O diálogo e o intercâmbio com a Associação Internacional e a consolidação das pesquisas contribuíram para o fortalecimento deste movimento no Brasil.

O terceiro período é o de desenvolvimento diferenciado que se inicia nos anos 2000 e tem sido representado pela refundação de associações, retomada de colóquios e pela emergência de novos autores e atores que têm fortalecido o movimento com novas publicações e ações, de onde emergem novas abordagens que visam responder a novas questões teóricas e metodológicas. Como fruto desse movimento, foi realizado na cidade de Porto Alegre, em 2004, o I Congresso Internacional sobre Pesquisa (auto)biográfica (CIPA), o qual oportunizou a criação de uma rede de pesquisa 
(1) Elizeu Clementino Souza (2006), no texto intitulado $A$ arte de contar e trocar experiências: reflexões teórico-metodológicas sobre história de vida e formação, tomando como referências autores como Pineau (1999), Pazos (2002) e Frago (2002) discute sobre as diferentes tipificacões utilizadas nas investigações no campo das abordagens biográficas. (auto)biográfica brasileira. O CIPA teve sua quarta versão no ano de 2010, na cidade de São Paulo.

O crescente uso das histórias de vida na formação fez surgir várias correntes e uma diversidade de denominações de abordagens, tais como: biografias, (auto)biografias, relato de vida, narrativa de vida. Contudo, os estudos que constituem o corpus dessas abordagens têm sido desenvolvidos na "encruzilhada da pesquisa, da formação e da intervenção". (PINEAU, 2006, p. 338)

Independente da abordagem tomada como aporte, o fato é que esse tipo de pesquisa utiliza-se de diferentes modos de narração para acessar e apreender as experiências formativas dos professores. Seja por meio de relatos orais e escritos, ou por meio de diários, memórias, cartas, entrevistas narrativas, fotografias, ateliês biográficos, as vidas são narradas e relembradas, valorizando-se suas singularidades.

Nóvoa e Finger (1988, p. 117) afirmam que essa abordagem deve ser entendida como "[...] uma tentativa de encontrar uma estratégia que permita o indivíduo-sujeito tornar-se actor do seu processo de formação, através da apropriação retrospectiva do seu percurso de vida". No entanto, o autor adverte que ela não deve ser compreendida apenas nessa dimensão, pois ela proporciona uma reflexão teórica sobre o processo formativo. Assim, para o autor, seria interessante pensar-se numa nova epistemologia da formação (grifo do autor).

Sabe-se que há algum tempo se buscam novos "modelos" para a formação de professores, a partir de aportes teórico-metodológicos que proporcionem um processo formativo de qualidade e que contribuam para a prática dos professores. Nesses processos, várias concepções foram elaboradas e têm exercido influências na formação docente, conforme abordaremos a seguir.

\section{As diferentes concepções sobre formação de professores}

A formação do professor exerce papel relevante no âmbito educacional, sendo alvo de estudos e críticas diversas. Os vários olhares lançados sobre os cursos de formação docente têm contribuído para a construção e reconstrução de concepções que fundamentam esses cursos em determinados contextos sociopolí- 
ticos e econômicos, e consequentemente, para o delineamento da identidade do profissional da docência.

Autores como Nóvoa (1992, 1999), Catani (1997), Garcia (1999), André (2001), Mizukami e colaboradores (2002), Lopes e colaboradores (2007), têm contribuído com análises, reflexões, críticas e propostas para a formação do professor, tomando como parâmetro a diversidade de denominações que têm caracterizado o professor nas últimas décadas do século XX, tais como: professor especialista, professor pesquisador, reflexivo, prático, competente, crítico.

Nesta perspectiva, Garcia (1999) apresenta algumas conceituações que usualmente têm fundamentado os cursos de formação inicial, das quais destacamos as seguintes: Orientação Acadêmica que prioriza o processo de transmissão de conhecimentos científicos e culturais tendo em vista a formação do profissional especializado em determinado conteúdo disciplinar; Orientação Tecnológica fundamentada nas investigações sobre processo-produto, esse tipo de orientação enfatiza a aprendizagem da docência decorrente de conhecimentos científicos por meio de técnicas de ensino; Orientação Personalista voltada para a pessoa do professor no processo de ensino e que objetiva proporcionar aos professores a capacidade de serem pessoas com autoconceito positivo; Orientação Prática, na qual se enfatiza o conhecimento prático, concebendo-se a experiência como a base de conhecimento sobre o ensino e o aprender a ensinar, a que se acede através da reflexão, que permite ao professor construir novas teorias e estratégias de ação para o enfrentamento de situações problemáticas; por fim, a Orientação Social-Reconstrucionista relacionada à teoria crítica; essa orientação dá ênfase à formação do compromisso ético e social do professor, buscando desenvolver sua capacidade de análise social do contexto em que é desenvolvido o processo de ensino e aprendizagem.

$\mathrm{Na}$ abordagem do prático reflexivo, enfatiza-se a relação teoria-prática como eixo de formação, concebendo-se a prática como espaço de construção e transformação de conhecimentos e não como local de aplicação destes. Mizukami e colaboradores (2002, p. 57), citando Valli (1992), elencam quatro níveis de reflexão que essa abordagem pode integrar, a saber. No primeiro nível, a Reflexão - na - ação, o conhecimento externo guia a prática tangencialmente; a situação é vista por si só, como fonte importante de conhecimento. No segundo nível, o Deliberativo, a reflexão sobre explicações, perspectivas e teorias competitivas entre si é um componente 
central da preparação de professores, "quase como uma precondição para a própria ação reflexiva". No terceiro, Personalista, "[...] a voz do professor, o crescimento pessoal e as relações profissionais constituem preocupações centrais". Por último, o nível Crítico"[...] deve considerar a escola e suas relações com a perpetuação de uma ordem social injusta e implica ajudar os professores a agirem em sala de aula, na escola e em outros lugares do sistema, de forma a corrigir as injustiças [...]".

Em síntese, as dimensões que envolvem a abordagem prática reflexiva trazem imbuída uma concepção de professor como profissional que aprende também com sua prática. Sua aprendizagem é caracterizada por um aprender fazendo - ensinando. É por meio da prática que ele experimenta, comete erros, toma consciência deles e cria novas estratégias.

Os diversos olhares direcionados à formação docente corroboram a acepção de que o professor é um agente de formação e de autoformação situado num contexto histórico-social; por isso, tem uma história e constrói outras histórias, por meio de diversas experiências pessoais e profissionais. Tais acepções colocam a experiência docente como elemento importante para a sua formação, contribuindo para o crescimento de estudos sobre a aprendizagem, processos formativos e identitários da docência que utilizam as histórias de vida como aporte teórico-metodológico para o acesso ao mundo pessoal e profissional dos professores.

Desta forma, os estudos sobre história de vida docente, por meio de abordagens biográficas com uso de narrativas, têm revelado a relação entre a pessoa do professor e a formação, a profissionalização, os saberes, a prática docente e o contexto em que esse se desenvolve. As investigações têm pontuado as vidas que há em cada relato e contribuído para o fortalecimento das identidades individual e coletiva dos professores.

Atualmente, vários autores se debruçam sobre esse tipo de investigação. Dentre eles podemos citar: Nóvoa (1992), Huberman (1992), Josso (2004), Pineau (2006) e Hernández (2006). De acordo com Nóvoa (1992), os estudos nessa área privilegiam objetivos teóricos, relacionados com a investigação; objetivos práticos, relacionados com a formação e objetivos emancipatórios, relacionados com a investigação-formação. Assim, cada estudo tem a sua própria configuração e busca focalizar três dimensões: a pessoa do professor, as práticas e a profissão. 
Em nosso caso, temos utilizado a abordagem tanto como dispositivo para a formação quanto para a investigação. No entanto, nesse artigo, trataremos do uso de narrativas no processo de formação continuada de professores em que temos atuado.

\section{A abordagem biográfica na formação continuada de professores: um estudo de caso}

Com base nos pressupostos apresentados de que a aprendizagem da docência não se inicia apenas na formação inicial, mas também nas relações com os professores ou familiares, intentamos desenvolver uma prática formativa, seja na formação inicial ou na continuada de professores, direcionada às reflexões dos processos que antecedem a formação e que influenciam na escolha da profissão e na performance docente.

O objetivo do trabalho desenvolvido foi fazer com que os professores refletissem sobre seus processos identitários na docência e que, assim, pudessem ter, para avaliar suas ações em sala de aula, além do aspecto teórico construído no curso, o aspecto da formação da subjetividade. Josso (2004, p. 41) comenta que "[...] se a aprendizagem experiencial é um meio poderoso de elaboração e de integração do saber-fazer e dos conhecimentos, o seu domínio pode tornar-se um suporte eficaz de transformação". Assim sendo, a escrita de si possibilita o reencontro com fatos e pessoas e a reflexão sobre as experiências que contribuíram nas escolhas e, portanto, um repensar de si mesmo e de suas ações.

Por meio da leitura empreendida sobre as narrativas, percebemos que a relação com a docência foi marcada por episódios diversos que constituíram e constituem as identidades das professoras narradoras. A opção pela profissão, para a maioria do grupo, foi influenciada por eventos da infância, seja por "herança" familiar, seja por "brincadeiras de meninas". Os relatos a seguir exemplificam as fontes de influências referidas.

Finalmente, comecei a lembrar que sou filha de professora, sobrinha de professora, irmã de professora, assim, conheci o magistério. (Wanusa)

Desde cedo eu gostava de brincar de 'escolinha'. Inicialmente, com minhas bonecas, posteriormente com meus sobrinhos e primos. (Andrea) 
(2) Termo utilizado pela professora para explicitar o processo pelo qual foi transferida do ensino infantil para a EJA, sem ser consultada $e$ sem ter alternativa de escolha.
As professoras lembraram-se, também, de seus antigos professores.

Professores que marcaram por sua postura rígida, tradicional, ou que impressionaram pelo carisma e afeto com os quais se dedicavam ao ato de ensinar e se relacionar com o aluno. De uma forma ou de outra, os sujeitos lembrados exerceram influência na escolha e na postura docente das professoras em pauta.

A entrada na carreira docente é marcada pelo choque da realidade, conforme identificado por Huberman (1992). Nas narrativas das professoras, o choque da realidade também fez parte de sua vida profissional. No entanto, o choque se deu não pela ausência de competência para relacionar a teoria estudada com a prática, mas pela ausência das duas, experiências e/ou conhecimentos. Em outras palavras, devido à falta de formação inicial em EJA ou mesmo de formação continuada e à falta de experiência em ensinar a adultos, algumas enfrentaram conflitos ao iniciar essa prática.

Diante dessa situação, senti um impacto enorme, por notar a diferença entre alfabetizar adultos e crianças. (Norma)

[...] naquele momento, não passava pela minha cabeça outra coisa senão os perigos do ensino noturno, a má qualidade do aluno, as complicações e dificuldades que eu teria por falta de experiência e aptidão. Fiquei apavorada! (Alba)

Outro aspecto da profissão apontado por elas, foi a impermanência no local de trabalho. Esse episódio é caracterizado tanto pela determinação política administrativa quanto por necessidades particulares do professor, e marca o início da experiência da maioria dos docentes com EJA, conforme se relata abaixo.

Tudo ocorria com tranqüilidade, pois me adaptei facilmente, no entanto, no ano seguinte, fui transferida para uma turma de EJA I.

(Norma)

Iniciei na EJA em 2001, por questões de necessidade de horários e não por afinidade. (Tamires)

Lembro-me da forma como recebi a notícia que tinha sido projetada ${ }^{2}$ para essa modalidade...era pegar ou largar. Acabei enfrentando o desafio para não sair da escola que eu gostava e gosto muito, até porque tinha a promessa de voltar para o diurno no ano seguinte. (Alba)

As informações acima são representativas de várias problemáticas que norteiam a EJA, que não fazem parte de nossa discussão neste momento. No entanto, não podemos deixar de aludir que 
os episódios acima revelam a falta de continuidade das atividades dos professores com um determinado público. Sendo o professor muitas vezes "projetado" de uma realidade a outra, sem que tenha completado seu ciclo de experiência ou vivenciado resultados do trabalho iniciado. Denota também, a falta de políticas públicas para a Educação de Jovens e Adultos, no que se refere à contratação de professores específicos para a área. Essa realidade influencia tanto no processo de profissionalização dos professores como de sua profissionalidade. Uma vez que além de explicitar a desvalorização profissional dos docentes, repercute na subjetividade do professor no que se refere não apenas ao seu valor enquanto pessoa como na qualidade de sua prática.

Os professores em seu dia a dia, inventam, criam e pesquisam sobre os seus instrumentos de trabalho. Nesse cenário de práticas alternativas, pesquisas, criação e recriação, os professores tomam suas atitudes diante dos dilemas da profissão e constroem, assim, a sua forma própria de ser professor. Esses saberes e fazeres foram revelados nas narrativas dos docentes, corroborando com a ideia de que a docência é uma arte e de que o professor como artista deve em seu dia a dia criar e construir meios. Nos relatos abaixo, as professoras contam como, cotidianamente, elas tentaram desenvolver uma prática de ensino que atendesse aos "novos" sujeitos pelos quais eram responsáveis.

[...] realizei atividades voltadas para suas realidades, na busca de si mesmo e no resgate da sua auto-estima, como: músicas, danças, dinâmicas, textos reflexivos, conversas informais, relatos pessoais, preenchimentos de fichas, simulação e documentos pessoais, gincana, emissão de vídeos, entre outras atividades. (Alba)

Eu procurava trabalhar com material que estivessem relacionados com sua realidade, pois não havia livro direcionado à Educação desse discente, era tudo muito difícil. (Raimunda)

Minha prática na EJA foi voltada para reflexões sobre a realidade... valorizando os conhecimentos e experiências já adquiridas pelos alunos...partilhando e descobrindo o que seria útil para suas realidades e assim, íamos construindo e fazendo a leitura do mundo. (Wanuza) Aprender pela experiência constitui a forma com que cada um tem de ser professor, de aprender a ser, de conduzir seu trabalho, de enfrentar as questões do dia a dia, como narrado pelas professoras. Parece-nos que o enfrentamento das demandas cotidianas de sala 
de aula, a busca por novas formas de fazer, acentuou os recursos experienciais, que por sua vez contribuiram na construção/transformação das identidades dessas professoras.

As narrativas revelaram o movimento constante que caracteriza a vida profissional e pessoal dos sujeitos em formação. Por meio dos escritos docentes, percebemos o processo permanente de mudanças que atinge as três dimensões do professor - a pessoa, a prática e a profissionalização - demandando novas posturas, novos processos identitários. Os depoimentos abaixo podem representar os movimentos identitários percebidos a partir das narrativas:

Ao longo da minha trajetória na EJA, fui me construindo aos pouquinhos e assumindo meu compromisso enquanto professora dessa modalidade, procurando novos significados para a aprendizagem a fim de integrar de forma dinâmica a leitura do mundo e a leitura da palavra. (Alba)

[...] a partir daí findaram meus questionamentos, e dei início ao que estava faltando, que era o embasamento teórico, para me tornar de fato e verdade uma professora da EJA... Comecei a elaborar melhor minhas propostas, meus planos de aula, aí, as coisas começaram a fluir de maneira a não me sentir mais uma intrusa na minha sala de aula. (Alana)

Ser professor implica em escolhas, em formação de uma performance específica. E as escolhas que fazemos em conjunto com as nossas posturas, diante do mundo, delimitam a nossa identidade. Os professores revelando sua vida, sua prática, seus conflitos, seus saberes, por meio dos memoriais, revelaram as diversas identidades docentes presentes naquele processo de formação.

\section{Considerações}

Ao desenvolvermos uma prática formativa utilizando-nos de narrativas de vida, consideramos a experiência dos professores como base para a sua formação e, portanto, buscamos valorizar seu processo de desenvolvimento profissional e pessoal, de uma forma interativa e dialógica, em que os mesmos pudessem sentir-se sujeitos de sua formação. Esta experiência nos proporcionou o conhecimento das representações dos professores tanto no âmbito biográfico, no momento em que narraram suas singularidades de ser professor, quanto no âmbito do social, no que diz respeito a sua profissionalização. 
No decorrer do processo formativo, os professores aventuraram-se na escrita de suas histórias, resgatando da memória os eventos que os constituíram professores. Refletindo sobre as histórias de vida, os sujeitos aprendentes foram desvelando a sua identidade, as influências que receberam para a escolha de ser professor, o como se tornaram professores, os desafios, as dificuldades e as alegrias da vida profissional e pessoal.

A partir das narrativas biográficas e profissionais, chegamos a algumas aproximações sobre a aprendizagem da docência em EJA das professoras narradoras. Observamos, entre as professoras, um processo de mudança de concepção sobre a docência em EJA. Ao iniciar a prática, as professoras chegaram à sala de aula com uma representação negativa dos sujeitos da EJA, baseada na ideia de que eram alunos do ensino noturno, com história de abandono escolar e, consequentemente, com defasagem de conhecimento, com problemas sociais que poderiam dificultar o trabalho. Além disso, a docência nessa modalidade de ensino foi concebida por elas como um desafio, devido à falta de formação para lidar com esses sujeitos. Essa realidade provocou um processo de reflexão das professoras sobre o seu fazer em sala de aula, levando-as a buscarem "novas" formas de ações pedagógicas que contribuíram para não se sentirem como uma "intrusa" na sala de aula, conforme narrado pela professora Alana.

Percebe-se, com isso, que entre o "choque da realidade", vivenciado pelas professoras ao iniciarem a prática com EJA, e o momento que desenvolveram novas ações, sentindo-se mais autônomas na sala e aula, houve uma dinâmica identitária que provocou um sentimento de pertencimento ao grupo de professores da EJA, como relatado pelas professoras Alba e Alana.

O uso das narrativas no processo de formação não serviu apenas para que as professoras refletissem sobre seus processos de formação para a docência, mas também proporcionou ao professor formador o conhecimento dos sujeitos em formação e um repensar sobre a forma deles aprenderem. Dessa maneira, o enfoque biográfico potencializa o olhar dos professores para si mesmo, para sua prática, para sua formação, no momento em que reconstituem a sua cultura, suas histórias, a partir de um movimento singular plural de sua existência. 


\title{
The educational narratives in teacher's education processes as a mechanism for reflection on teacher learning in teaching youth and adults.
}

\begin{abstract}
The article talk about issues concerning the use of narratives in teacher education of Youth and Adults (EJA). The study presents as analysis the process of EJA teaching constitution of the five teachers from public schools in Fortaleza-Ce. The data were constructed from written narratives of the teachers during the course of continuing education. The theoretical approach adopted was (auto) biographical in a perspective research-education and interactive-dialogical model. (BASTOS, 2003; HERNÁNDEZ, 2006; JOSSO, 2004; PINEAU, 2006; SOUZA, 2006, 2008) To reflect on teacher education we seek contribution of authors like Huberman (1992), Garcia (1999) Mizukami et al. (2002). The study shows up the teacher's personal experience as the foundation for the teacher education, being initial or continued. The grasped analisys revealed that, at first, the teachers conceived the EJA teaching as a challenge, which, faced by seeking "new doings" in the classroom. This attitude contributed to a process of identifying them with the teaching in this type of education.
\end{abstract}

Key Words: Adult education. Teachers, training of. (Auto)biography.

\section{Referências}

ANDRÉ, Marli (Org). O papel da pesquisa na formação e na prática dos professores. Campinas, SP: Papirus, 2001.

BASTOS, Maria Helena Camara. Memórias de professoras: reflexões sobre uma proposta. In: MIGNOT, Ana Chrystina Venâncio; CUNHA, Maria Teresa Santos (Org.). Práticas de memórias docentes. São Paulo: Cortez, 2003.

CATANI, Denice B. Docência, memória e gênero: estudos sobre formação. São Paulo: Escrituras, 1997.

DELORY-MOMBERGER, Christine. Biografia e educação: figuras do indivíduo-projeto. Tradução de Maria da Conceição Passegi, João G. da Silva Neto, Luis Passegi. São Paulo: Paulus; Natal: EDUFRN, 2008.

GARCIA, C. Marcelo. Formação de professor: para uma mudança educativa. Porto: Porto Editora, 1999.

HERNÁNDEZ, Fernando. História de vida de professores: o que se pensa na Espanha? Revista Educação em Questão, Natal, v. 25, n. 11, p. 224234, jan./abr. 2006.

HUBERMAN, Michael. O ciclo de vida profissional dos professores. In: NÓVOA, António (Org.). Vidas de professor. Tradução de Maria dos Anjos Caseiros e Manuel F. Ferreira. Porto: Porto Editora, 1992. p. 31-62.

JOSSO, Marie-Christine. Experiências de vida e formação. Tradução de José Claudino e Júlia Vieira. São Paulo: Cortez, 2004. 
LOPES, Amélia et al. Fazer da formação um projecto: formação inicial e identidades profissionais docentes. [Porto] : Livpsic, 2007.

MIZUKAMI, Maria da Graça N. et al. Escola de aprendizagem da docência: processos de investigação e formação. São Carlos, SP: EDUFSCar, 2002.

NÓVOA, António. O passado e o presente dos professores. In: Profissão, professor. 2. ed. Tradução de Irene L. Marques, Regina Correia, Luisa Santos Gil. Porto: Porto Editora, 1999.

(Org.). Vidas de professores. Tradução de Maria dos Anjos Caseiros e Manuel F. Ferreira. Porto: Porto Editora, 1992.

; FINGER, Matthias. O método (auto)biográfico e a formação. Lisboa: Centro de Formação e Aperf. Profissional, 1988.

PINEAU, Gaston. As histórias de vida em formação: gênese de uma corrente de pesquisa-ação-formação existencial. Educação e Pesquisa, São Paulo, v. 32, n. 2, p. 329-343, maio/ago. 2006.

SOUZA, Elizeu Clementino. A arte de contar e trocar experiências: reflexões teórico-metodológicas sobre história de vida e formação. Revista Educação em Questão, Natal, v. 25, n. 11, p. 22-39, jan./abr. 2006.

. Modos de narração e discursos da memória: biografização, experiência e formação. In: PASSEGGI, Maria da Conceição; SOUZA, Eliseu Clementino de. (Auto) biografia: formação, territórios e saberes. Natal, RN: EDUFRN; São Paulo: Paulus, 2008.

Artigo submetido em 15/02/2012 e aceito para publicação em 12/06/2012. 